\title{
EN EL SIGLO XXI, ¿CUÁL SERÁ EL MARCO JURÍDICO PARA QUIENES YA MURIERON?
}

\author{
Pilar Castells Ballarin
}

\section{Introducción}

$\mathrm{E}$ ste artículo toma en cuenta procesos vigentes que sólo permiten aún vislumbrar las líneas que trazan los fenómenos y comportamientos ciudadanos y su respuesta legal o su vacío jurídico.

Los fenómenos que se citan y los problemas que se evidencian para su análisis son el fruto de varias miradas. Por un lado, se comparte de manera más extensa un estudio realizado en Panamá, entre 1997 y 1999, que tuvo el objetivo de ofrecer una visión global del comportamiento e interés de su conjunto social alrededor de la percepción sobre el trato que merecen los muertos. Las referencias a Panamá, en este texto, son algunas de las conclusiones de esa investigación. Se retoman porque es un país cuya problemática, conflictos y comportamientos comparten otros muchos países y, sobre todo, las ciudadanías situadas en el modelo de lo que conocemos como "Occidente": un modelo que olvida en su escala de valores al ser muerto ya que considera indeseable la muerte. Por otro lado, comparte la mirada sobre una serie de cambios jurídicos que han significado un punto de inflexión en cuanto a la inclusión de los seres muertos en los Derechos Humanos. Entre estos cambios jurídicos se advierten

Pilar Castells Ballarin, Universidad de Barcelona. como especialmente relevantes: la Carta Europea de Salvaguarda de los Derechos Humanos en la Ciudad, ${ }^{1}$ el caso conocido como El Negro de Bañolas, España, y el proceso de recuperación de la memoria histórica - levantando e identificando los cadáveres de fosas comunes—, realizado en muchos países. Otra mirada es la de la ciencia, en la que los resultados de varios estudios legitiman o respaldan comportamientos considerados como supersticiosos.

\section{El estado de las cosas}

Se tiende a admitir en Occidente que la muerte y los muertos han quedado relegados no sólo de la vida cotidiana sino del interés de los propios ciudadanos; sociedad enfocada en el bienestar centrado entre el nacimiento y la muerte de la persona. Algunos análisis ya clásicos (Ariès, 1975 y 1977; Elías, 1982; De Miguel, 1995), iniciados a partir de década de 1950 del siglo $\mathrm{xx}$ en varios países, reflexionaban sobre el alejamiento de la muerte de la vida familiar y comunitaria por dejar a los enfermos y moribundos en manos de expertos e instituciones; afirmaban también que métodos en incremento como la incineración de cadáveres promovían el olvido casi inmediato del ser muerto. Por otra parte, el ser muerto $-\mathrm{y}$ toda la actuación 
posterior de los sobrevivientes para mantener o no su memoria y cuidado_ — ha sido objeto de estudio bajo el concepto generalizado de ritos funerarios. En su mayoría estos estudios son etnológicos y se centran en destacar la particularidad de un rito, detallado en profundidad. El caso es que este tipo de estudios han dejado una sensación de exotismo, incluso de anomalía. Hay una predisposición a encajar esos comportamientos como ajenos a la sociedad hegemónica occidental de la que somos parte. La diversidad de culturas $y$ de enfoques en el manejo de los rituales de duelo, de alejamiento del núcleo comunitario y de trascendencia, en el tipo de creencias en el más allá, son adornos para la sociedad occidental, puesto que hay una pérdida de funcionalidad de esos rituales, en la que el orden y control social considera hechos relativos a la muerte. Tales prácticas culturales no pueden ningunear esos hechos. Su funcionalidad es meramente privada y asegurada por la existencia de asociaciones o cofradías para su ejercicio.

Históricamente, en Occidente, el destino de los muertos ha sido competencia de la religión; de las autoridades civiles y sanitarias; de las creencias muy particulares de los deudos; de las circunstancias extraordinarias que cada país ha atravesado; del olvido temporal; de las modas. En definitiva, se trata de un paradero rutinario pero bastante azaroso, realmente. Ahora, mucho más que en veinte o treinta años atrás, la ciudadanía de la casi totalidad de Occidente invierte parte de su energía en ocuparse de los muertos. Lo hace desde perspectivas y con expectativas esencialmente distintas de los marcos de control e higiene que se generalizaron como modelo de comportamiento desde la Ilustración, ${ }^{2}$ o desde el interés previo que le otorgaron las religiones.

El texto que comparto se interesa por el ser muerto y por los escenarios que puede ocupar en todo o en parte. Trata del motivo que impulsa al conjunto de la población a esforzarse y gastar recursos en realizar actos que considera muy importantes, también cuestiona decisiones de las autoridades; analiza si son comportamientos residuales o se trata de creaciones vivas en evolución constante. Actualmente, es importante conocer a fondo los motivos y el valor que tienen las decisiones tomadas por las personas en relación con sus muertos. Vivimos en una época que es escenario de grandes desplazamientos humanos y encuentro o choque de culturas, conflictos armados, desastres naturales, ejecuciones en masa..., que provocan centenares de muertes o desplazan el suelo de los cementerios sacando los huesos a la superficie, las fosas comunes y los desaparecidos por razón de conflicto, junto a otros fenómenos ahora considerados importantes por la población. En estas circunstancias caben las preguntas: Quienes deciden y planifican ¿pueden seguir desconociendo la realidad de las expectativas de la población en relación con sus/los muertos? ¿La salvaguarda de la memoria de los muertos es un asunto privado o concierne a la comunidad, actuando a través de las estructuras del Estado? ¿Cómo conviven otros mandatos religioso-culturales en un Estado laico de origen hegemónico cristiano? ¿Resulta funcional tratar los problemas derivados del choque entre las medidas legales y las expectativas de los diferentes grupos humanos en un modelo que ha quedado obsoleto porque sigue pensando en un ser humano sólo como ser vivo?

El modelo del que nace este estado de las cosas es el fruto de un proceso iniciado hace tres siglos, va desde la hegemonía religiosa en todos los órdenes de la vida a la hegemonía de la razón o materialismo en los mismos órdenes. Mientras una religión era hegemónica, contra otras religiones y creencias y para el sistema conjunto vida-muerte, la muerte y los muertos estaban bajo su control. Cuando la Razón ocupa el lugar de la Religión el proceso se invierte, y la razón se ocupa del control de la muerte y los muertos, mientras que la religión queda subordinada además de tener que compartir espacio con otras creencias. 
El momento culminante del modelo se dio en 1948, Declaración Universal de los Derechos Humanos, mismo que acaba convirtiéndose en el marco más aceptado para regular las relaciones humanas en todo el mundo. Esta Declaración legitima la libertad de culto y su ejercicio. Su vocación es universal e incluyente de todas las culturas y religiones, en tanto no se opongan a los principios declarativos.

En Europa y en América — desde la Independencia - se sigue el siguiente perfil: los muertos quedan clasificados por competencias: la definición de muerte, su declaración, el trato con el cadáver y su destino, son competencia civil; los ritos funerarios son competencia de la religión y de cada cultura en la que esa religión se desarrolla, convirtiéndolos en práctica religioso-cultural. Durante años ha sido funcional, pero parece que ya no lo es. De hecho, acciones ciudadanas de muy diversas modalidades han evidenciado los agujeros de ese modelo, que remite constantemente a que el ser humano es aún un ser en proceso de definición, de ahí que la condición de estar muerto se encuentre ahora en esa situación.

\section{Mirada 1. Panamá como referencia: Repaso de una investigación ${ }^{3}$ y de sus conclusiones}

Panamá es un país moderno que está plenamente incorporado a los procesos de interés planetario. Desde el siglo XIx ha integrado en sus comunidades grupos humanos de todo el mundo, en mayor o menor número, que han ejercido sus creencias en suelo panameño. Esta característica lo hace interesante como referencia para otras localizaciones en que el fenómeno mundial de la migración y diversidad de etnias y culturas es más reciente. Conocer los enfoques y estrategias de otro país en aras de resolver un problema esencialmente similar aunque con características diferentes conviene para tener más elementos de análisis a la hora de tomar decisiones. En Panamá, el modelo racional de comportamiento social — clave de Occidente- se implantó con todas las consecuencias en el periodo de construcción del Canal americano, primera década del siglo xx: con la racionalización del sistema sanitario, de los cementerios, de los censos; todo ello promovido por las autoridades del Canal. Aunque, los mecanismos de subordinación de la Iglesia católica al Estado se iniciaron en la Independencia.

El poder que la Iglesia tenía hasta la Independencia era grande; era quien daba el reconocimiento legal para la ciudadanía porque eran los únicos documentos que existían y que eran el certificado de bautismo, que sólo que usted tuviera el certificado de bautismo tenía usted derecho a la ciudadanía en un lugar determinado. La Iglesia era también la que tenía los cementerios en los que se enterraba a todo el mundo y, además, el derecho a la herencia lo daba la Iglesia, al dar el certificado de defunción de una persona que había sido enterrada con los ritos eclesiásticos, pues éste era el único documento que le daba derecho de estar en posesión de la herencia a los hijos y a los nietos o a quien fuera que se daba por heredero en el testamento, porque ya con eso estaba el documento que la persona había muerto. Al llegar la Independencia los gobiernos liberales crean los cementerios nacionales oficiales, le quitan poder económico, político, social a la Iglesia al dar el certificado de defunción oficial, igual con el certificado de inscripción oficial de nacimiento, y con los hospitales, que hasta ese momento estaban todos en poder de la Iglesia, igual con el matrimonio civil. Igual pasó con los reconocimientos para los títulos, de modo que la Iglesia era la única que tenía universidades en América, hasta la Independencia, y todos los títulos los daba la Iglesia, pues. Por eso es muy normal que la Iglesia se hubiera opuesto al reconocimiento de los gobiernos liberales, no sólo como dicen muchas tesis liberales - por oscurantistas, sino porque había una enorme cantidad de intereses 
económicos, políticos y sociales, aparte de toda la cuestión ideológica. ${ }^{4}$

En la investigación que se llevó a cabo, interesada en el discurso sobre los muertos, se aisló una constante como clave de todas las acciones y decisiones: el concepto descanso en pazo descanso de los muertos. Es un deseo que ampara conductas muy diversas y que actúa como caja negra. Quien lo pronuncia sabe que no será discutido. Para lograrlo se toman medidas afines o muy distintas por cada grupo socioeconómico o religioso, por origen rural o urbano, indígena o mestizo; pero todos quieren garantizar el bienestar de sus muertos, traducido en un reposo sin perturbaciones.

Con estos elementos se puede decir que actúa como un concepto comodín, o sea, instrumento de justificación y aprobación de todas esas conductas, en un momento en que carecen de un marco legitimador que las ampare. ¿Se maneja como un instrumento de espera, hasta que los muertos sean nombrados y se incorporen a la sociedad de los Derechos Humanos como ha sucedido con las mujeres, los niños y las minorías étnicas? Es un interrogante que no tiene respuesta aún; pero sí es seguro que hay una brecha abierta entre la estructura social abstracta que genera normas y discursos siempre tópicos sobre la muerte, los efectos de la misma, y el discurso vivo de la gente concreta. En esta brecha es imposible no destacar la actitud creativa y protagonista de los ciudadanos y las estrategias elegidas para resolver los conflictos con los diferentes sistemas de control, que se contrasta a menudo con lo que ofrecen los marcos institucionales del Estado a través de sus aparatos y normas, así como de los sistemas religiosos y asociaciones religioso-culturales.

\section{Fuentes de información}

Se trabajó con una muestra total de 150 personas con diferentes niveles de intervención y respondiendo a objetivos distintos. De ese modo, catorce personas representan el conocimiento profesional y profundo de diferentes aspectos: mandato religioso: católico, hindú, mahometano, baha'í; cementerios municipales y privados, y funerarias; profesiones que actúan al margen del mandato religioso o civil, rezadoras; el trato con los muertos en la morgue; la planificación de las empresas municipales de servicios funerarios; la actitud de los diferentes grupos indígenas ante la muerte, el destino de los muertos y la donación de órganos. Diecisiete personas informan, desde una posición de liderazgo o experticia, sobre escenarios y conductas en áreas campesinas, áreas especiales de desplazamiento, refugiados, niños, barrios con identidad propia, minorías religiosas, cambios de religión, nuevas creencias. Veintinueve personas complementan con matices sobre los mismos temas y ayudan a cohesionar una visión más viva. Treinta personas jóvenes informan puntualmente en su conocimiento sobre la rutina a seguir cuando alguien muere y su voluntad de donar órganos. Sesenta personas más confirmaron, debilitaron o añadieron gradaciones a las anteriores. La prensa escrita, las normas legales, las fotografías que se tomaron y los actos que se presenciaron en vivo, se relacionaron entre sí, en lugar de ser analizados independientemente, dado que se pretendía encontrar el centro del movimiento, señalar los protagonistas principales y trazar con todo ello el esquema de otra visión de la realidad. De ese entramado se presentan unos cuantos subtítulos.

\section{Negociaciones entre culturas y mandato: rompiendo fronteras}

Comparar la exposición pública de un muerto en su propia área cultural con otro del mismo orden en un área cultural distinta es un ejercicio que ayuda a dudar sobre las verdades y normas que, desde cada religión, se proclaman como conditio sine qua non. ${ }^{5}$ Atribuir a la incineración la virtud de olvidar al muerto puede ser 
defendible en algunos lugares pero no en Panamá; quienes la eligieron, por ser más barata que inhumar, siguen guardando las cenizas en una iglesia o cementerio y pagan alquiler por ello. Un muerto musulmán en Panamá no podrá ser visto como uno en Palestina, porque teniendo la misma religión la ejercen en áreas de cultura hegemónica distinta. El palestino en su área cultural puede ser trasladado a hombros sin ataúd, yendo en el soporte que manda el Islam. El musulmán de Panamá tiene que ir en un ataúd hasta el borde de la fosa, donde previa negociación con el cementerio privado se le reubica en el soporte que señala su mandato religioso.

\footnotetext{
Nosotros enterramos el cuerpo sin ataúd, eso ya está permitido aquí por ley, no por ley pero sí bajo los reglamentos del Jardín de Paz; ellos saben que esa es la forma de enterrar de nosotros y nos lo permiten. Luego se hace ese entierro. Se entierra, se pone el cuerpo de la persona en la fosa, se le pone lo que llamamos "petates", dos petates para tapar el cuerpo, entonces luego de los petates van tiras de playwood o de un... playwood delgaditas arriba; se le ponen nuevamente petates y entonces es lo que también creo que se hace en la religión cristiana, que todos los presentes echan puñados de tierra en al ataúd... en los petates. ${ }^{6}$
}

El ataúd, estrechamente relacionado con los muertos del grupo cristiano, es símbolo común pero de características y mensajes diferentes, según el grupo que lo use. Por ejemplo, las personas del ámbito católico y de origen rural si hacen el ataúd a medida para el muerto lo ajustan al máximo para que no quede espacio entre el cuerpo y la caja. Si compran un ataúd estándar, rellenan todos los huecos con ropa.

... una de las costumbres que tienen en mi pueblo es que cuando la persona muere, si es niño le llenan con sus ropitas más bonitas o preferidas, lo mismo con el adulto, ya sea hombre o mujer. Se le llena el ataúd con sus ropas de preferencia, o sea que la persona se las lleva, y si el ataúd le queda un poquito grande lo tapan todo con ropa para que no quede ninguna apertura, porque se dice que si la persona no le llegan los pies a la parte final del ataúd, se lleva a cualquier familiar. ${ }^{7}$

El ataúd se rellena con ropa, que no queden huecos, porque si queda hueco el muerto se llama a otro muerto. La cruz es de madera y se hace con el ataúd; no se cobra, lo demás es de pago de la familia. Cualquier muerto, el ataúd se rellena todos los huecos con ropa, que no quede ningún espacio libre, porque dicen que si queda espacio entre el cuerpo y el ataúd "el muerto llama a otro muerto", o sea que de inmediato muere otra persona de esa familia. ${ }^{8}$

Pasear un muerto en su ataúd para rendirle homenaje es un acto que se ha aceptado para identificarse - un subgrupo de una comunidad urbana - frente a terceros en un área determinada de la capital. Tuvo su fuente de inspiración en un ritual de despedida que hacían las bandas de delincuentes a sus muertos. El muerto, no ya necesariamente un delincuente, se convierte en punto de referencia y sello de marca de toda una zona de la ciudad conformada por varios barrios que han recibido cientos de inmigrantes, después de la invasión del país en 1989, donde una parte fue bombardeada y se incendió por completo, desestructurando el núcleo social. El homenaje lo hacen a quienes eran del barrio, no a los recién llegados. Se logra que una conducta limitada a un grupo, delincuentes, se extienda a otros grupos y se convierta en identidad de barrio, como marca de distinción frente a forasteros. Un comportamiento, inicialmente espontáneo, arraiga como símbolo propio, de identidad, y se regulariza e impone.

El choque permanente entre los mandatos religiosos minoritarios, pero bien organizados en asociaciones que respaldan sus acciones, y las ordenanzas creadas en un país que heredó un modo de hacer distinto, se resuelve por la vía de la negociación. Mahometanos y judíos, 
que entierran sin ataúd, lo usan; sin embargo para trasladar al muerto hasta el cementerio - privado o de su confesión — lo sacan del féretro y acomodan según su mandato, contando con el consentimiento negociado de la administración del cementerio en cuestión. La prohibición de autopsia entre los miembros de la confesión judía se resolvió por la misma vía de negociación con las autoridades civiles en un caso histórico. ${ }^{9}$

Estas confesiones residentes en Panamá desde el siglo XIX, más o menos de forma continua, se agruparon inicialmente en asociaciones creadas con el fin de conseguir un entierro y ritual conforme a su mandato religioso, que conseguían comprando una parcela y creando su propio cementerio confesional. Actualmente persisten esas mismas asociaciones, pero la tendencia es comprar un terreno en un cementerio privado para su propio uso. Los indostanos de confesión hindú, que incineran — salvo a niños de corta edad-, contratan con un cementerio privado el uso de la cámara de incineración y de una capilla para la ceremonia religiosa.

\section{Roles de género y cambios}

Mujeres y varones mantienen, en mayor o menor medida, comportamientos distintos con los muertos. La muerte implica para algunas mujeres restricciones sociales muy estrictas, siguiendo el patrón de mayor o menor control que, en otras áreas de la existencia, cada grupo asigna a uno u otro sexo. La estancia en otro país de cultura dominante diferente permite ciertos cambios en los límites establecidos que, quizá, en el país de origen se darían igual pero con mayor conflicto.

-Ch. Las mujeres aquí en Panamá, los acompañan hasta el cementerio como dice ella (T.), hasta donde está el lugar para sentarse, y las personas rezan y todo lo demás, pero cuando llevan el ataúd de allí para proceder al proceso de cremación, los hombres son los únicos que acompañan, ya sea mujer u hombre el que ha muerto.

-P. ¿Por qué las mujeres no pueden ir?

-Ch. Eso es porque desde la India lo practican así, inclusive, o sea, que una persona se murió y las mujeres, como le digo, llegaban hasta las afueras del pueblo nada más, verdad. Y de allí las mujeres se retiraban y los hombres pues llevaban al muerto en vehículo o como sea.

\section{-P. ¿Aunque fuese una mujer?}

-Ch. Exactamente, son los hombres únicos del pueblo [los que van] hasta el cementerio, son ellos los que van, pero por lo menos aquí, las mujeres en Panamá, llegan hasta el cementerio, verdad. [De] Allí al salón en que se puede rezar y rezan y todo lo demás hasta ahí, y después de allí en adelante los hombres son los únicos que siguen. ${ }^{10}$

Las mujeres constructoras de ataúdes en una funeraria popular, amas de casa, tuvieron que enfrentarse a sus propios miedos y creencias; ${ }^{11}$ cambios de rol — habían aprendido y asumido que la construcción de ataúdes estaba tradicionalmente asignada al género masculinoy de actitud no sólo en ellas mismas como constructoras sino en sus familias y amistades y vecinos, con quienes hubo que argumentar sobre la dignidad de su trabajo. Fue un proceso que afectó a la propia identidad asumida, de género, y afectó del mismo modo a la sociedad más inmediata, también en las creencias sobre lo que corresponde hacer a varones y mujeres.

Al principio no estaban seguras de hacer los ataúdes. Sólo la falta de recursos y los costos de los cajones las empujaron adelante. Decían que hacerle el cajón al muerto 'se lo lleva a una por delante'. Yo les tenía que argumentar con las funerarias... " ¿vieron lo vivos que están y lo ricos que son? Ya, déjense de tonterías que nadie se muere por hacerle la caja al muerto".

La funeraria pudo existir porque era un proyecto sin ánimo de lucro. Las funerarias de Panamá echaron el 
grito al cielo, pero no pudieron hacer nada porque ellas son empresa y esto era distinto. Se sacaba 12 dólares por ataúd, que venía representando una compensación por el tiempo de confección. ${ }^{12}$

\section{Algunos medios de socialización clave}

La ausencia de un sistema oficial de socialización con las conductas a seguir en caso de muerte — salvo algunos mandatos religiosos de carácter muy estricto, como el mahometano- no implica que no estén establecidos unos patrones convencionales, patrones que se van renovando con acontecimientos que permiten una difusión masiva de los rituales seguidos. Es el caso de los funerales de personajes públicos especialmente representativos. Por otra parte, el uso de determinados símbolos o la recurrencia a determinados patrones nos permiten rastrear el orden económico, social, religioso y cultural del muerto, aunque algún símbolo haya permeado otras capas donde no es tradicional su existencia, por ejemplo, el ataúd, utilizado por toda la sociedad de Panamá, sin importar su pertenencia a una religión o grupo socioeconómico, al punto que el ataúd es símbolo de dignidad.

\footnotetext{
Durante quince días en las casas no se hablaba de otra cosa que del lujo de los ataúdes, que antes no se habían visto nunca de tan caros; de lo triste que fue ver la tripulación metida en bolsas de plástico negras, mientras que a los hebreos e indostanos los sacaban metidos en esos ataúdes de lujo y cada uno en su carroza, mientras que los panameños ni carroza traían. ${ }^{13}$
}

\section{La autorización para trasplantes de órganos}

La redefinición de la muerte es un tema que está en la calle y no sólo en manos de expertos en los hospitales. Se puede concluir que si bien existe una voluntad ampliamente favorable a la donación de órganos para trasplante, en el grupo de cultura católica, mayoritario, se trata de una voluntad condicionada a que la persona beneficiaria sea alguien "conocido, joven, buena persona, o que le ayude a seguir trabajando". A efectos prácticos, esta voluntad en sí misma no significa nada; la ley garantiza el anonimato de la persona receptora, aún así la donación real es muy baja porque quienes toman la decisión se preocupan de no perturbar el descanso del muerto.

\footnotetext{
Ahora mismo hay mucha gente en lista de espera; casi cerca de 200. Algunos podrían haberse resuelto ya si hubiera más donantes reales, o sea, de los que al morir su familia no tiene problema en que le extraigan las córneas. Pero falta mucha educación e información sobre todo esto. El problema también es que no aumentan los donantes voluntarios, y tampoco se hace seguimiento de los voluntarios [potenciales], así que, a veces, nos encontramos que [a] la familia cuando se les pide, no aceptan. ${ }^{14}$
}

La iniciativa de los legisladores de establecer la preferencia para ser receptor en caso de identificarse como donante es hábil pero no va al fondo del asunto. Se parece mucho a la filosofía imperante de ir parcheando en lugar de profundizar qué han descrito algunos estudios (Rodríguez y Montserrat, 1994; Le Breton, 1994). La filosofía contraria — donar órganos del propio cuerpo constituye una burla para el muerto-, pero argumentada desde otro ángulo ético, ${ }^{15}$ desde las minorías étnicas del país, ni siquiera es tenida en cuenta por el debate. Otros argumentos de rechazo son por mandato religioso.

Se puede establecer que, en materia de donaciones de órganos, el conocimiento previo de asociar la muerte con señales de paro del corazón, cuerpo helado, y signos de cadaverización, es un antecedente que choca con la decisión experta diagnosticadora bajo el criterio de 
muerte cerebral —específicamente utilizado para extraer órganos o tejidos para trasplantes- Un diagnóstico, este último, que no conlleva necesariamente el cese del corazón, el aspecto negruzco o la frialdad de la piel. Incluso la misma certeza que puede dar el uso estricto y adecuado de la tecnología a los expertos actúa como causa de incertidumbre en el resto de ciudadanos, al observar en los monitores una línea con picos que indica que el corazón no ha muerto.

Cuando llegué al hospital, mi hijo estaba en cuidados intensivos. Allí el jefe médico me dijo que estaba muerto y que si aceptaba firmar para donar órganos. Yo estaba conmocionada y dije que sí, pero al mirar las cámaras de los aparatos había líneas que oscilaban. Pregunté qué eran y me dijo la enfermera que era el corazón. Siempre me ha quedado la duda de qué se siente con la muerte cerebral, si él sufría y escuchaba y ese tipo de cosas. Yo no creo en nada, pero sí pienso que el no saber más de estos asuntos nos coloca en indefensión. ${ }^{16}$

Nos dimos cuenta que la muerte es un proceso mucho más importante de lo que parece y que manipular el cuerpo o enterrarlo tan pronto como aquí se acostumbra no es muy beneficioso para quien ha muerto. Por otra parte, no creemos, ahora, que los trasplantes sean la única alternativa, con todo esa propaganda en los medios que hace sentir culpable a la gente que no dona sus órganos. ${ }^{17}$

Los jóvenes ven la donación como un acto altruista, pero es más una idea que una realidad. En el ámbito cultural mayoritario, los jóvenes intuyen que sus padres no permitirán la extracción de sus órganos si llegara el caso, salvo que conste expresamente, y tal expresión no suele constar, de momento. Los jóvenes rurales expresan directamente que su voluntad de donar está condicionada a que la persona receptora sea niña o joven o persona adulta que aún tenga obligaciones que cumplir y la donación se lo permita. En definitiva, unos deseos poco funcionales con lo previsto por la ley.

Las tecnologías como la del trasplante de órganos y tejidos están en plena efervescencia, cabe pensar que en un plazo no tan largo decaerán en favor de otras tecnologías más eficaces y menos conflictivas. De ahí que habrán aportado una excelente experiencia de planificación y organización, coordinación y colaboración mundial e interdisciplinar, junto al provocar cuestionamientos sobre la certeza de muerte y otras inquietudes en el conjunto de la población, como quizá no había sucedido en muchos años.

\section{La práctica de rezar y la profesión de rezar}

Hay prácticas, como rezar, que se repiten en todas las creencias, en el ámbito católico y en otros se ha creado la categoría de rezadora o rezador, que es la persona que sabe rezar y dirigir el rezo. Una persona similar existe en los musulmanes e hindúes. Aunque no se le ha aislado del conjunto de prácticas, no procede como categoría independiente. La rezadora existe para dar respuesta a algunas expectativas de grupos determinados de católicos que se han visto abandonados por su jerarquía como consecuencia de la evolución en sus mandatos y prohibiciones, que ha seguido la Iglesia católica desde el Concilio Vaticano II. Vive en las ciudades y en las áreas rurales y se renueva en su función adaptándose a los tiempos.

La Iglesia católica prohíbe todo tipo de superstición a propósito de la muerte, supersticiones que presuponen espiritismo. Por ejemplo, la idea de que el muerto viene a beber y entonces se pone un vaso de agua con una ramita de albahaca como se hace en muchos lugares. Ese tipo de prácticas, que son totalmente supersticiosas, la Iglesia no quiere de ninguna manera que se tengan. ${ }^{18}$

$$
\text { ¿En qué consiste el altar? }
$$


En ponerle una sábana blanca, se pone un crucifijo y una vela; también se acostumbra poner un vaso de agua con albahaca y, posteriormente, en la noche se reza un rosario. Un rosario por noche, ya que después de que la persona se saca del hospital y se realiza el sepelio, entonces se empieza a rezar todos los días por nueve noches. Ya sea por ejemplo si las personas quieren rezar tres rosarios, cinco o siete, tienen que ser impares. No se debe rezar par.

Asi que durante las nueve noches todos los vecinos, amigos y familiares se reúnen en la casa de los dolientes para acompañarlos y rezar.

Yo... aprendí a rezar desde que era muy niña, no recuerdo exactamente cuántos años yo tenía cuando aprendí a rezar en un velorio, porque hace muchos años en los cuales yo rezo y hasta la fecha, pues; actualmente en donde muere un amigo o persona donde yo pueda apoyar, yo voy y les apoyo...

El agua con albahaca representa y se oculta porque según nuestra tradición, si la persona murió con sed, ella va a regresar en cualquier momento de esas nueve noches a tomar agua, por eso se pone debajo de la mesa en un lugar que no esté visible al público. $^{19}$

Las personas de otras religiones, musulmanes e hindúes, rezan en los ritos funerarios pero no contemplan la figura de la rezadora o el rezador como complementaria de su religión, como figura aislada de lo que sus autoridades religiosas admiten. El mismo comportamiento genera figuras distintas según se trate de un ámbito u otro. Y, en definitiva, rezadores sólo se encuentran en el ámbito católico.

No, nosotros no tenemos rezadores. Lo que sí tenemos son personas muy versadas en cuanto a la oración, lo que vendrían siendo una especie de sacerdotisas. Al contrario de la religión cristiana, que los sacerdotes no se casan, en la religión de nosotros, musulmana, sí se casan, hacen su familia y muchas veces son las mismas esposas de los sacerdotes que han estudiado para eso, las que dirigen la oración en las mujeres cuando nos reunimos, eso sí, el velorio, que se me pasó decirle, tanto de hombres como de mujeres, sólo es para las mujeres, o sea, las mujeres velamos a los hombres y a las mujeres. ${ }^{20}$

Frente a la moderna gestión de la muerte por parte de profesionales altamente especializados, las rezadoras renuevan sus lugares de acción, afianzándose en las ciudades - además de continuar en las comunidades rurales-, y fortalecen prácticas que no tienen más respaldo que el amparo de la tradición, pero que significan uno de los pocos ejes de socialización existentes ajeno a los mandatos religiosos, civiles, o de gestión empresarial.

\section{La presión ciudadana sobre los límites del sistema}

La revitalización del interés demostrado por la ciudadanía hacia los muertos antiguos o recientes es una realidad frente a la cual la clase política se defiende y no sabe cómo reaccionar. Lo que atañe a los muertos está empezando, también, a trascender del ámbito de lo privado a lo público. Y empieza a configurarse como un asunto de responsabilidad pública más global, de garantías para los muertos, en abstracto. Garantías que no pueden dejarse bajo la responsabilidad de las familias o de la administración de los cementerios sino que requieren un conjunto de soluciones de mayor alcance.

Los enfoques antiguos ya no coinciden con los enfoques y expectativas actuales de la ciudadanía. Por eso, se crean problemas donde se creía que no habría —la decoración de los cementerios en los que se sigue colocando flores a pesar de la prohibición—; se toman decisiones imprevistas — depositar las urnas de ceniza en nichos de cementerios o iglesias en lugar de lanzarlas 
al aire o al agua o enterrarlas en el jardín y ahorrarse el costo del lugar sagrado_; se mantienen conductas consideradas injustificadas hasta para el sistema religioso al que se pertenece — poner un vaso de agua junto al muerto para que no tenga sed, en el caso de los católicos.

Las orientaciones de las autoridades religiosas en el ámbito católico, relacionadas con los ritos de muerte entre sus fieles, cumplen una función rutinaria y se mantienen acciones que la Iglesia rechaza como superstición, mientras que las personas las justifican diciendo que son para que el muerto descanse en par: Detrás de esas conductas está la convicción de que el muerto sigue viviendo, aunque se diga lo contrario en un discurso en el que hábilmente se afirma lo que se está negando, del estilo: ¿crees en brujas?; no, pero hay. Lo que la Iglesia católica considera que es una superstición no lo es para otros sistemas de creencias, en los que tales prácticas tienen amparo y legitimación.

Se ha probado que no es únicamente la falta de planificación de los cementerios municipales lo que genera problemas; en los cementerios privados, por ejemplo, planifican muy bien sus acciones y hacen firmar la conformidad de las mismas a sus clientes, pero éstos se niegan a cumplir medidas que enfrenten sus ideas. La más común y problemática es la prohibición de poner flores en el cementerio, ya que es sistemáticamente vulnerada. El problema de los cementerios no es sólo de gestión, es también, y sobre todo, el choque emergente de una concepción ciudadana del cementerio, viva y creativa $v$ s unos gestores que obedecen a modelos importados y crematísticos - los cementerios privados - o a modelos obsoletos - los municipales.

Hay un paréntesis y falta de consenso respecto al tipo de contrato que se establece con los habitantes más antiguos de los cementerios o con los cementerios fuera de uso. $^{21}$ Hay cambios en la estética de los cementerios más actuales, orientándose preferentemente hacia un aspecto de parque o jardín, pero no todos los cambios son previsibles, ni todo lo previsto se cumple. Así, la menor carestía de la incineración, junto al levantamiento de la prohibición de cremar por la Iglesia católica y a las modernas cámaras de incineración en los cementerios privados, favorecieron para que eligiera esta opción 45\% del sector católico del grupo socioeconómico alto residente en la capital, frente a la otra de inhumación. Ahora bien, el destino de las cenizas no fue la casa ni el jardín ni el mar, como muchos presuponían, sino los cementerios donde se compran o alquilan nichos para su guarda o dependencias de las iglesias habilitadas para el mismo cometido.

La población quiere enterrar a sus muertos dignamente, con ataúd y ritual, no en la fosa común y por la puerta de atrás. Quiere cementerio propio, que se mantenga en condiciones favorables y donde se siga respetando a los fallecidos. Pero conseguirlo no es tan sencillo. Los conflictos, la falta de recursos, el abuso de poder o la incursión en la ilegalidad y la falta de un marco legal adecuado, conducen a las grietas del sistema. Un siglo después de las grandes migraciones que han configurado la diversidad de grupos humanos y creencias en Panamá, se siguen repitiendo los mismos patrones: los grupos que tienen recursos o están organizados son los que pueden negociar para que sus muertos sean respetados según sus creencias; quienes no cumplen esa condición es muy probable que tengan su final en una fosa común y bajo el estricto cumplimiento de las ordenanzas. Esto significa que sólo unas buenas redes en el ámbito privado, familiar o de asociaciones, son capaces de asegurar las expectativas de dignidad.

El trato del sistema de poder hacia los muertos ha sido y es de control, pero su ejercicio no está resultando muy satisfactorio, lo que puede indicar, a su vez, el declive del sistema. En todo el país aparecen conductas ilegales que se convierten en rutina y hasta en marca de identidad de un grupo. La creatividad y la propia iniciativa, aunque contrarias a las normas legales, son 
un rasgo que define el momento actual. Ejemplos: enterrar de noche, ${ }^{22}$ rendir honores a un muerto por pertenecer a un barrio paseándolo con el ataúd a hombros por las calles, sonando música y bebiendo alcohol (conductas todas ellas expresamente prohibidas); o crear una funeraria popular para asegurarse un ataúd al morir.

\section{Los desaparecidos}

El análisis del impacto sufrido por la población como consecuencia de los hechos de la invasión ${ }^{23}$ con cientos de muertos que fueron a fosas comunes junto a quienes nunca aparecieron, apuntaba a que el dolor fundamental era por los muertos que habían sido tratados como basura, metidos en bolsas de plástico, sin identificar, y sin cristiana sepultura - que equivale a decir que fueron tratados indignamente-, con el agravio comparativo de que los gringos que murieron en Panamá recibieron honores en su país, EUA. El fenómeno de las muertes masivas, los cementerios clandestinos y los desaparecidos es mundial y recurrente. En toda América Latina nadie ha querido dejar esos muertos en el olvido. En Panamá, Argentina u otros países, las mujeres ocupan un lugar protagónico para que se encuentren, identifiquen y devuelvan a las familias y a la sociedad a todos los que no descansan.

Al principio sólo se hablaba de que gracias a los gringos teníamos la democracia. Pero cuando empezó a hablarse de desaparecidos y sacaron a los cadáveres de las fosas comunes todos los panameños nos sentimos vencidos. Porque ningún vencedor trataría así a sus muertos. $^{24}$

A una vecina que le mataron el hijo en la invasión dice que se le presentaba en sueños. La mujer estaba asustada. Cuando al hijo lo encontraron en la fosa del Jardín de Paz y ya ella lo enterró, no le vino más en sueños. ${ }^{25}$
De aquí se deducen ciertos elementos considerados impropios de un ser humano y ajenos por completo al concepto de descanso: estar en una bolsa de plástico en lugar de un ataúd, estar sin identificar; no haberse separado oficialmente de la sociedad. Tales circunstancias no disminuyen con el paso del tiempo, hecho comprobado en las exhumaciones que se hicieron en algunos cementerios de restos antiguos, colocándolos en bolsas de plástico a la espera de que los familiares pagaran los alquileres pendientes. Las fotografías de esas bolsas en la prensa horrorizaron a todo el mundo.

\section{El cementerio: símbolo elocuente del control político-social de la muerte}

Los cementerios son espacios controlados por autoridades municipales o empresas privadas que durante años no han significado un problema importante, sin embargo, largos años de desatención han desembocado en que tanto los cementerios municipales como los privados enfrenten problemas de frustración entre la población y autoridades por el incumplimiento de lo previsto en los objetivos de los cementerios.

Esta frustración se debe a la evidencia de la precariedad del descanso de los inhumados; en este contexto se encuentran las denuncias de brujería y profanación, el peligro físico por deslizamientos de tierras, la ocupación de tumbas por gente extraña a la misión del cementerio y la venta de cementerios en desuso para otros fines. Hay un grave problema de espacio para toda la gente que muere, fruto de un cúmulo de errores de imprevisión y de planificación -28 años sin construir un nuevo cementerio en el área del país de mayor crecimiento demográfico es mucho tiempo- Hay un desbordamiento de los controles administrativos y de las responsabilidades entre autoridades municipales y familiares de difuntos que repercute en el mantenimiento de las tumbas 
existentes. Hay bolsas de plástico llenas de huesos de cadáveres por falta de pago de los alquileres bajo responsabilidad de quienes administran los cementerios, a la espera de que se paguen las moras y sin llevar los restos a la fosa común por miedo a darles un destino fatal. Guardar cadáveres es un negocio o una obligación, pero sus gestores no olvidan que los allegados de un muerto desean que esté en pa‡. Por eso, cuando se incumplen las normas de pago no hay reclamaciones judiciales, de ahí que las administraciones de los cementerios esperen el máximo tiempo posible antes de exhumar los restos con pagos morosos. También es significativo que los símbolos cristianos de la muerte son preferidos por una gran mayoría de la población respecto a un paisaje más ajardinado con césped y exento de puntos de referencia floral, escultural o de cruces, usados por los católicos para señalar que allí hay un muerto.

\section{Otros enfoques para legitimar algunas prácticas "mal" vistas}

Uno de los aspectos más destacados del modelo imperante en Occidente es la separación brutal que hace de la vida y la muerte, como si se tratara de compartimentos estancos; frente a otros sistemas de pensamiento en que la vida y la muerte son un todo único. Pero, también, frente a la íntima opinión de la ciudadanía que, con su comportamiento y justificación global del descanso del muerto, está expresando que cree que el muerto tiene conciencia de lo que sucede. Un muerto tiene sed, por eso le colocan un vaso con agua; necesita reconfortarse con el calor del corazón de los que le quieren, colocan velas; necesita alegría, ponen flores; necesita que le recuerden, visitan el último lugar del que se desprendió su conciencia: el cementerio; necesita ánimos para no cansarse, rezos durante los nueve días que suponen dura el viaje. Todos estos actos no se hacen por tradición, sino por una íntima convicción de que el muerto está vivo en otra dimensión y sabe lo que se hace aquí. Por supuesto, ninguno de estos actos está avalado ni por la religión católica ni por las ordenanzas civiles. La estrategia seguida, hasta mejores épocas, cuando alguien cuestiona todos esos actos, es la de ampararse en el comodín de que es para que el muerto descanse en pa\%: Esto produce el efecto mágico de terminar el debate.

La muerte tiene otros enfoques para opciones que no se difunden por Occidente hasta hace muy poco. De todos ellos, dos posibilidades muy alejadas culturalmente de las propias raíces ${ }^{26}$ han hecho mella recientemente en este país. Son el budismo tibetano y las enseñanzas de Don Juan a través de los libros de Carlos Castaneda. La revitalización del interés en la muerte, fruto de las incertidumbres e interés renovados, obligan a buscar otros conocimientos fuera del ámbito de la propia religión o creencia y más allá de la ciencia de enciclopedia. Por ejemplo, el conocimiento sistematizado que tiene el budismo tibetano de la trayectoria de la conciencia después de la muerte y de su salida del cuerpo físico es muy atrayente para quien, desde el fondo de su pensamiento, no ha renunciado a la esperanza o intuición de que el muerto no muere del todo y que lo que personalmente está haciendo para el descanso del otro está bien hecho digan lo que digan.

De alguna manera, muchas preguntas que nadie me respondía o que yo no iba a preguntar a los sacerdotes o a los conocidos porque ya sé su respuesta, las he encontrado en el Libro Tibetano de los Muertos. ${ }^{27}$

Algunos de esos conocimientos, pues, están resultando esperanzadores, atractivos, o bien están en sintonía con los anhelos e incertidumbres actuales. En pequeños círculos, personas universitarias o profesionales intentan buscar en dichos sistemas nueva información sobre la existencia más allá de la muerte, porque las explicaciones o falta de ellas de los sistemas convencionales han quedado obsoletas para quien se 
cuestiona aspectos como la conciencia y su ubicación, la esencia de la existencia, o simplemente se han adentrado en el concepto de la reencarnación.

\section{Mirada 2. La ciudad y los seres humanos muertos}

La ciudad es el ámbito "natural" del cambio de modelo, pero sólo se han dado algunas iniciativas a la altura del contexto actual en ciertas urbes; iniciativas que se citan como novedad y que amplían el horizonte del ser humano. A fines de la década de 1990 se inicia, en Europa, un proceso de consenso en torno a una Carta Europea de Salvaguarda de los Derechos Humanos en la Ciudad. Barcelona fue la ciudad encargada de presentar el borrador inicial. Este borrador incuía un artículo sin precedentes: Artículo 3. "Derecho a la libertad cultural, lingüística y religiosa". Apartado 4. La ciudad guarda el recuerdo de quienes ya murieron y asegura el respeto, ornato y dignidad de los cementerios. Incorpora a los muertos y los lugares destinados a ellos al marco de los Derechos Humanos.

Es la primera vez que el ser muerto está amparado y legitimado en el marco de los Derechos Humanos. El significado de esto es que cualquier comportamiento relativo a los muertos y sus escenarios ya no es una conducta privada, culturalmente ajena pero tolerada y objeto de negociación entre personas. Por el contrario, los seres muertos, su dignidad de seres humanos y su memoria, son competencia de la ciudadanía y de sus estructuras, por tanto, de interés publico, con todas las consecuencias.
Las consecuencias jurídicas y sociales son numerosas: desde la duración de la memoria para las tumbas más antiguas que no tienen ya descendientes que las cuiden, hasta los límites al respeto de mandatos religiosos que se confrontan con las ordenanzas municipales sobre salubridad e higiene.

\section{Mirada 3. Legitimación de comportamientos a través de la ciencia}

Interrogantes como ¿mueren los muertos?, o ¿qué es lo que muere en los muertos?, suelen tener este tipo de afirmación en la población: los muertos mueren en su cuerpo de ahora, pero siguen viviendo y saben lo que pasa aquí; lo que muere en los muertos es su cuerpo y se sabe porque se descompone. Esos interrogantes se los repiten los científicos desde enfoques diferentes, algunos (Korotkov, 1998) apuntan en el resultado de investigaciones recientes que la íntima convicción de las personas comunes no está tan alejada de lo que han comprobado: que el cuerpo del ser declarado muerto mantiene registros de su campo bioenergético de forma intermitente durante varios días, lo que podría indicar que existe conciencia individualizada después de la muerte y que guarda una vinculación real con el cuerpo declarado muerto. Pero, ¿cómo se enlaza esta situación con la demanda de órganos consecuencia de la tecnología de trasplantes? En este tema el cuerpo que se manipula está declarado muerto, pero no tiene las características de lo que muchas personas admiten como estar muerto. 
A B I E R T A

\section{Ejemplos de creatividad ciudadana como generadora del cambio de modelo}

Cuadro 1. Ejemplos de nuevas conductas ciudadanas para asegurar la dignidad de los muertos y su aporte a los criterios existentes

\begin{tabular}{|c|c|c|}
\hline Caso/ País & Descripción & Aporte \\
\hline $\begin{array}{l}\text { “El Negro de Banyoles". } \\
\text { España. }\end{array}$ & $\begin{array}{l}\text { Se reivindica el descanso de un muerto } \\
\text { disecado y expuesto desde hace casi un siglo } \\
\text { en un museo. La llamada de atención proviene } \\
\text { de una sola persona sin otra relación con el } \\
\text { muerto que ser miembro del género humano. } \\
\text { Se inicia en 1992, provoca un gran debate } \\
\text { público y finaliza reconociéndose el derecho } \\
\text { del muerto a descansar en paz. El muerto es } \\
\text { enterrado en el año } 2000 \text {. }\end{array}$ & $\begin{array}{l}\text { El descanso de un muerto es de } \\
\text { interés del género humano, de la } \\
\text { sociedad en su conjunto. }\end{array}$ \\
\hline $\begin{array}{l}\text { Guatemala, Chile, Argentina, El } \\
\text { Salvador, Panamá, España, } \\
\text { Balcanes, Irak (recientemente). }\end{array}$ & $\begin{array}{l}\text { La búsqueda de los cadáveres de los desapa- } \\
\text { recidos por razón de conflicto para darles } \\
\text { sepultura. }\end{array}$ & $\begin{array}{l}\text { Se denuncia y se exigen recursos } \\
\text { públicos para recuperar los cadáveres. }\end{array}$ \\
\hline $\begin{array}{l}\text { Flores en el lugar de una muerte } \\
\text { trágica. España, México, } \\
\text { Panamá. }\end{array}$ & $\begin{array}{l}\text { Colocar flores y renovarlas por largo tiempo } \\
\text { en el lugar donde ha sucedido una muerte } \\
\text { trágica. }\end{array}$ & $\begin{array}{l}\text { Las flores, en el inventario colectivo, } \\
\text { representan el alma o se dirigen a ella. } \\
\text { Se renueva el contacto con el alma. }\end{array}$ \\
\hline $\begin{array}{l}\text { Carta Europea de Salvaguarda } \\
\text { de los Derechos Humanos en la } \\
\text { Ciudad. Barcelona y ciudades } \\
\text { europeas adheridas. }\end{array}$ & $\begin{array}{l}\text { Artículo 3. Derecho a la libertad cultural, } \\
\text { lingüística y religiosa; Apartado } 4 \text {. La ciudad } \\
\text { guarda el recuerdo de quienes ya murieron y } \\
\text { asegura el respeto, ornato y dignidad de los } \\
\text { cementerios. }\end{array}$ & $\begin{array}{l}\text { Incorporación de los muertos y los } \\
\text { lugares destinados a ellos al marco } \\
\text { de los Derechos Humanos. }\end{array}$ \\
\hline $\begin{array}{l}\text { Uso del testamento vital, al am- } \\
\text { paro de la Declaración de los } \\
\text { Derechos Humanos y la Biome- } \\
\text { dicina del Consejo de Europa, } \\
1997 .\end{array}$ & $\begin{array}{l}\text { Se incorpora en el testamento vital el trato que } \\
\text { se desea recibir una vez muerto - - teniendo en } \\
\text { cuenta que se está muerto cuando así declara } \\
\text { una persona competente- - Se pretende evitar } \\
\text { con ello la manipulación del cuerpo durante, } \\
\text { al menos, tres días. }\end{array}$ & $\begin{array}{l}\text { Se amplía, como en el caso anterior, } \\
\text { el concepto de ser humano. Un } \\
\text { cadáver sigue siendo humano y en } \\
\text { virtud de serlo tiene derechos que } \\
\text { se pueden invocar. }\end{array}$ \\
\hline
\end{tabular}

Elaboración propia a partir de notas de prensa, Carta de Salvaguarda de Derechos Humanos en la Ciudad, y notas personales. 


\section{Algunas reflexiones a modo de conclusión}

Aunque no todo quien muere descansa, a todos preocupa que no sea así. El concepto descanso en pazes un concepto comodín. Vivimos una época de cambios, pero aún persisten los tópicos asertivos del modelo materialista para identificar, nombrar y explicar los fenómenos. Argumentar en contra es complejo y laborioso. Nadie, en cambio, se atreverá a decir que un muerto no debe descansar en paz, porque está acuñado socialmente que los muertos deben descansar en paz. Desde las funerarias hasta las esquelas de los periódicos y cualquier medio de expresión lo repite incesantemente. De este modo se produce, desde la ciudadanía, una apropiación de lo socialmente admitido y se invoca para justificar prácticas no admitidas.

Un cementerio significa mucho más que un espacio físico administrado de forma pública o privada para cumplir el objetivo principal que se le ha marcado durante más de un siglo: el de una guarda salubre y controlada de los cadáveres. Si algún hilo conductor une su pasado con su presente ése es el de la memoria. La memoria de los que descansan eternamente. Esa memoria se ha dejado en manos de la familia porque para el Estado la memoria de los muertos, en abstracto, no era de interés. La memoria de personas destacadas ha sido una referencia, durante cierto tiempo. La memoria del aporte de cada ciudadano individual y colectivamente no ha ocupado su pensamiento, como prueban las definiciones de cementerios durante todo el siglo xx: lugar de ubicación de cadáveres.

La presencia de un cementerio - del tipo que seaproyecta la sombra de seres que ocuparon grandes posiciones o pasaron anónimamente, que vivieron en la prehistoria o experimentaron tecnologías recientes; pero todos dependen de quienes les sobrevivieron y la tarea de su mantenimiento merece ser abordada de un modo nuevo, más allá de las viejas ideas de la Ilustración y de los límites de la religión. El mismo concepto cementerio se ha apropiado de las nuevas tecnologías, de las nuevas concepciones del espacio, de la superación de los límites planetarios y, por tanto, tiende a ir más allá de un espacio físico y de su control municipal. La oferta mundial se adentra en posibilidades como los cementerios virtuales, los cementerios en el espacio aéreo, los cementerios de diseño, los campos de fútbol como reposo de los restos de sus socios y otras situaciones hasta hace poco impensables. El cementerio se concibe, desde estas posibilidades, superando su marco territorial, el de la ciudad, la comunidad, el lugar sagrado, para abrirse a otros espacios bajo diferentes perspectivas.

Otro punto que da lugar para la reflexión se da en torno al encuentro entre enfoques diferentes que toman en cuenta la vida y la muerte, y las consecuencias que de ello se derivan en el trato con los muertos. Por ejemplo, una preocupación en círculos reducidos pero con capacidad para presionar es el trato que se sigue con los cadáveres — que lo son por declaración biomédica - y el que se considera debería seguirse. En buena medida, esta preocupación surge del conocimiento de otros enfoques y experiencias sobre el proceso de la muerte y la misma concepción de la vida, entre los que destaca el budismo tibetano. Cuando muchas personas educadas en el estado del bienestar o que han luchado para alcanzarlo profundizan en ese enfoque se plantean seriamente asegurar que no se manipule el cuerpo de la persona declarada biomédicamente muerta. Trato difícil de conseguir en los hospitales y en el marco de la legalidad estricta de las ordenanzas municipales. Un libro muy reciente ${ }^{28}$ promueve aprovechar la oportunidad que ofrece el marco legal del testamento vital — documento sobre voluntades anticipadas - en los países donde éste se prevé, para indicar el trato que se desea recibir y las conductas a seguir con el cuerpo una vez muerto. Todo ello en aras de lograr un cambio de existencia favorable; 
posibilidad que se complicaría en caso de manipulación del cuerpo durante los días siguientes a la muerte.

\section{E1 horizonte que se dibuja}

Emergen dos posibles grandes líneas de ampliación del enfoque oficial de la muerte y los muertos. Una es la línea del marco global en que se va a desenvolver el destino físico del ser humano que ahora no se considera tal, sino cadáver. La opción que parece más plausible en un futuro próximo es la que tenga como referencia la Carta de Salvaguarda de los Derechos Humanos en la Ciudad: "Las autoridades municipales cultivan la historia de su población y respetan la memoria de los difuntos, asegurando el respeto y dignidad de los cementerios". En la misma línea de ampliar la concepción del ser humano y adentrarse en la muerte está la posibilidad del testamento vital, en pleno debate en Europa y con muchas posibilidades legales a raíz de la Declaración de los Derechos Humanos y la Biomedicina del Consejo de Europa, 1997.

Otra línea, que también afecta al trato con los muertos, tiene que ver con la necesidad de conocer más y mejor sobre la vida, la muerte, la conciencia y dónde se ubica, qué es el ser humano. Cuestiones todas que buscan su respuesta en el marco ciudadano, más allá de las fuentes de definición tradicionales. Es probable que, en breve tiempo, pueda configurarse desde este proceso otra manera de hacer y otra perspectiva del cuerpo, la vida y la conciencia, que incorporen los cambios de enfoque apuntados sobre la propia concepción de la muerte y el estar muerto.

\section{Apunte final}

La muerte y los muertos están en proceso de cambio en la percepción de la ciudadanía. Tarde o temprano, el proceso de redefinición y su rol en la sociedad actual tendrán que darse. Faltan estudios sobre el problema que: 1. evidencien en varios lugares fenómenos de cambio; 2. los fenómenos descritos sean abarcadores, más que centrarse básicamente en especificidades; 3 . desechen los lentes de rito exótico, mirando siempre a otros grupos y se mire al propio o similar; 4 . analicen estrategias novedosas de solución de problemas para definir líneas de tendencia.

Finalmente, concluir que si todos vamos a morir es conveniente que prestemos un poco de atención al asunto sin confiar demasiado en soluciones a la carta de nadie.

\section{Notas}

${ }^{1}$ Se aprobó en Saint-Dennis, Francia, el año 2000.

${ }^{2}$ El modelo occidental, centrado en la Razón y en un ser humano vivo, se puede rastrear en la descripción de los pueblos y sus cementerios que realiza Pascual Madoz en España (1845-1850), y en la normativa municipal sobre cementerios de Panamá o de cualquier otro país. El eje es la salubridad.

${ }^{3}$ Pilar Castells. Investigación realizada entre 1997-1999, base de la tesis doctoral: "El descanso de los muertos: un concepto en evolución".

${ }^{4}$ Pilar Castells. Ibid. Entrevista 17: obispo católico.

${ }^{5}$ Por otra parte, las conductas que se alejan de su norma para cumplir otros mandatos en otras áreas culturales ponen en evidencia la superioridad del mandato secular — racional sobre el cultural-religioso-, al que este texto se refiere como predominante y problemático.

${ }^{6}$ Pilar Castells. "El descanso de los muertos: un concepto en evolución”. Entrevista 15: Mujer indostana musulmana.

${ }^{7}$ Pilar Castells. Ibid. Entrevista 18: rezadora, licenciada en pedagogía.

${ }^{8}$ Pilar Castells. Ibid. Entrevista 9: dirigente campesina/ estudios de secundaria completa/ cultura católica.

${ }^{9}$ Accidente de aviación ocurrido en julio de 1994.

${ }^{10}$ Pilar Castells. Ibid. Entrevista 16: mujer indostana hindú.

${ }^{11}$ Por ejemplo: quien le hace el ataúd al muerto será el próximo muerto, sin cuestionar por qué en las empresas funerarias no pasa eso.

${ }^{12}$ Pilar Castells. Ibid. Entrevista 5: ingeniera industrial.

${ }^{13}$ Pilar Castells. Ibid. Entrevista 12: antropóloga.

${ }^{14}$ Pilar Castells. Ibid. Entrevista 28: portavoz del Banco de Ojos. 
${ }^{15}$ Pilar Castells. Ibid. Entrevista 19: cacique general y presidente del Congreso General Kuna: "En nuestra cultura existe el hecho de que cuando una persona muere hereda a sus hijos o sus hijas con bienes materiales, un cayuco, algo que la persona muerta haya usado lo hereda a sus hijos; pero el hecho de donar algo de nuestro cuerpo no está dentro de nuestra cultura; esto se ve muy mal. ¿Por qué no lo aceptamos? Porque parece como burlarse de la persona muerta. Por eso ese temor de los viejos de morirse aquí [en la ciudad de Panamá], como ellos tienen conocimiento de eso [extracción de órganos para trasplantes], ellos piensan 'qué me van a hacer aquí, la gente en el hospital', cuando tienen una enfermedad, 'mejor me muero allá [en la Comarca], yo no sé que me van a hacer ahí [en el hospital]'. Entre los jóvenes sí varía. Algunos están de acuerdo, otros no están de acuerdo". ${ }^{16}$ Pilar Castells. Ibid. Rueda 4 (conversaciones libres).

${ }^{17}$ Pilar Castells. Ibid. Rueda 4 (conversaciones libres).

${ }^{18}$ Pilar Castells. Ibid. Entrevista 17: obispo católico.

${ }^{19}$ Pilar Castells. Ibid. Entrevista 18: rezadora (maestra jubilada).

${ }^{20}$ Pilar Castells. Ibid. Entrevista 15: mujer indostana musulmana .

${ }^{21}$ Este problema es común a todos los países: incluso en México, el día de muertos hay tumbas "olvidadas", porque ya no hay familia (ámbito privado) que se ocupe de ellas y las autoridades administrativas/municipales no lo tienen previsto en sus funciones.

${ }^{22}$ Pilar Castells. Ibid. Entrevista 2: dirigente campesina. "Cada vez más se está enterrando de noche; yo ya hace tiempo que no he visto un entierro de día. Creo que es por el calor, pero también porque de día se está trabajando y casi no puede ir la gente a los entierros. De noche todo el mundo está en casa y va mejor".

${ }^{23}$ Invasión de tropas estadunidenses en Panamá, diciembre de 1989.

${ }^{24}$ Pilar Castells. Ibid. Rueda 3. Anexo 4. (Manifestaciones realizadas sin intervención externa.)

${ }^{25}$ Pilar Castells. Ibid. Rueda 3. Anexo 4. (Manifestaciones realizadas sin intervención externa.)

${ }^{26}$ El budismo es una práctica que entró en Panamá con las inmigraciones chinas, pero no así el budismo tibetano. La santería, otra práctica prestigiada, es un sistema más enraizado culturalmente.

${ }^{27}$ Pilar Castells. Ibid. Rueda 9 (conversaciones libres).

${ }^{28}$ Lama Djinpa (Borja de Arquer). Buddha, materialismo y muerte. pp. 363-366.

\section{Bibliografía}

Ariès Philippe, 1975, Essais sur l'bistoire de la mort en Occident du Mogen Age à nos jours, Editions du Seuil, Paris.

—, 1977a, L'bomme devant la mort/ 1. Le temsp des gisants, Editions du Seuil, Paris.

-,1977b, L'bomme devant la mort/2. La mort ensawagée, Editions du Seuil, Paris.

Barbro Dahlgren, Jordan (compilador), 1993, Coloquio (III) de Historia de la Religión en Mesoamérica y Áreas afines, Universidad Nacional Autónoma de México/ Instituto de Investigaciones Antropológicas, México, "La influencia de los cementerios en la salud pública" por Martha Eugenia Rodríguez, pp. 125-131; "Psicosis colectiva y religión" por Ernestina Jiménez-Olivares, pp. 136- 143.

Bobbio, Norberto, 1991, El tiempo de los derechos, Sistema, Madrid.

Breton [Le], David, 1994, "Lo imaginario del cuerpo en la tecnociencia”, REIS 68 (Revista Española de Investigaciones Sociológicas), octubre-diciembre, Centro de Investigaciones Sociológicas, Madrid, pp. 197-210.

Brissest, Demetrio E, 1997, "Los fieles difuntos", en Historia 16, año xxII, núm. 259, Madrid, pp. 100-109.

Carozzi, María Julia, 1999, "La autonomía como religión: la nueva era", Alteridades (monográfico dedicado: Antropología de los movimientos religiosos), Año 9, Núm. 18, julio-diciembre, Universidad Autónoma Metropolitana, Iztapalapa, Departamento de Antropología, México, pp. 19-38.

Casado María y Graciela Sarrible (editoras), 1995, La mort en les ciències socials (Actes de les jornades realitzades a la Facultat de Dret, Universitat de Barcelona, 3 al 5 de noviembre de 1994), Universitat de Barcelona.

Castaneda, Carlos, 1981, El dón del Aguila, EMECE, Buenos Aires, 1998.

—, 1984, El fuego interno, Editorial OMGSA, México; Editorial Diana; Edivisión.

—, 1987, El conocimiento silencioso, Gaia, Madrid, Colección Nagual.

—, 1993, El arte de ensoñar, Diana, México, 1994.

Castells, Pilar, 2001, "El descanso de los muertos: un concepto en evolución”, Barcelona (Tesis doctoral. Dirigida por Josep A. Rodríguez. Universidad de Barcelona).

Dalai Lama y Howard C. Cutler, M. D., 1998, El arte de la felicidad, Grijalbo Mondadori, Barcelona, Reimpresión mayo de 1999. 
De Miguel, Jesús M., 1995, "El último deseo: Para una sociología de la muerte en España", REIS 71-72 (Revista Española de Investigaciones Sociológicas), pp. 109-156.

Elías, Norbert, 1982, La soledad de los moribundos, FCE, Colección Fin del mundo, México.

Grof, Stanislav y Cristina, 1980, Más allá de la muerte, Debate, Madrid.

Guénon, René, 1990, El hombre y su devenir según el Vedanta, CS, Buenos Aires.

Gyatso, Tamding (Guese), 1997, Muerte y reencarnación según el budismo tibetano, Ediciones Amara, Hospitalet de Llobregat.

Juan Jerez, Montserrat y Josep A. Rodríguez Díaz, 1994, “El cuerpo humano ante las nuevas tecnología médicas: Hacia una redefinición del nacimiento y la muerte", REIS 68 (Revista Española de Investigaciones Sociológicas), octubre-diciembre, Centro de Investigaciones Sociológicas, Madrid, pp. 173-196.

Kapleau, Philip, 1990, El renacer budista. La rueda de la vida y la muerte, Árbol Editorial, México.

Korotkov, Konstantin, 1998, Light after Life: A Scientific Journey into the Spiritual World, Backbone Publishing Company, NJ-USA.

—, 1998, 1999, Aura and Consciousness: New Stage of Scientific Understanding, St. Petersburg division of Russian Ministry of Culture, State Editing \& Publishing Unit "Kultura", San Petersburgo (Rusia).

Kübler-Ross, Elisabeth, 1985, La muerte un amanecer, Sirio, Málaga.

—, 1997, La rueda de la vida, Ediciones B, Barcelona.

Labdron, Machig, 1987, “La exposición de la transformación de los agregados en una ofrenda de alimentos...", en Anila Rinchen Palmo, Comentario de la práctica del CHOD, Traducción directa del tibetano, Capítulo IV, Editions Dzambala, Landrevie Montignag (reeditado).

Lama Djinpa (Borja de Arquer), 2002, Buddha, materialismo y muerte, Ediciones Librería Argentina, Madrid.

Lazarus, Richard, 2000, Proceso a la muerte. La realidad del más allá, Océano, México.

Lodö, Venerable Lama, 1982, Las enseñanzas del bardo. El camino de la muerte y la resurrección, Ibis, Hospitalet de Llobregat, 1992.

López-Navidad A., J. Kulisevsky, F. Caballero, 1997, El donante de órganosy tejidos. Evaluación y manejo, Springer-Verlag Ibérica, Barcelona.

Madoz, Pascual, 1845-1850, Diccionario Geográfico-EstadísticoHistórico de España y sus posesiones en ultramar, Madrid.
Montaigne, Michel de, 1998, Ensayos, Edición de Dolores Picazo y Almudena Montojo, Cátedra, Madrid.

Moody, Raymond, 1977, Vida después de la vida, EDAF, Madrid. Morin, Edgar, 1994, El hombre y la muerte, Kairós, Barcelona. Nagarjuna y el séptimo Dalai Lama (Kaysang Gyatso), 1997, La guirnalda preciosa y el cántico de las cuatro reflexiones, Traducido al inglés por Jeffrey Hopkins y Lati Rimpoché en colaboración Anne Klein, Traducido al castellano por Andrés M. ${ }^{a}$ Mateo, Editorial Diana, México.

Padma Sambhava, 1996, El libro tibetano de los muertos, Edición y traducción del tibetano por Ramón N. Prats, Ediciones Siruela, Madrid.

—, 1996, El libro tibetano de los muertos, Traducción del tibetano con comentarios de Francesca Fremantle y Chögyam Trungpa (1975), 'Troquel, Buenos Aires.

—, 1994, El libro tibetano de los muertos, Encontrado por el yogyi Karma-ling-pa, Traducido al inglés e introducción y comentarios de Robert A.F. Thurman (1994), Traducido al castellano por Miguel Portillo (1994), Kairós, Barcelona.

Rivera, Pedro y Fernando Martínez, 1998, El libro de la invasión, Prólogo de Elena Poniatowska, FCE, México.

Senghe, Jampel (Guese), 1984, Sueños, muerte y bardo, Ediciones Dharma, Alicante, 1992.

Sogyal Rimpoché, 1992, El libro tibetano de la vida y de la muerte, Urano, Barcelona, 1994.

—, 1995, Destellos de sabiduría. Reflexiones sobre la vida y la muerte, Urano, Barcelona, 1996.

Tai Situ Rimpoché, 1995, La muerte y el morir, Ciclo de conferencias dadas por su Eminencia Tai Situ Rimpoché en Samyê Ling, Escocia, en el mes de agosto de 1988, Traducción del inglés por Jimpa Gyamtso, Asociación Dhagpo/ Samye Dzong, Barcelona.

Tipler, Frank J., 1994, La física de la inmortalidad. Dios y la resurrección de los muertos, Alianza Editorial, Madrid, 1996.

Turner, Bryan S, 1994, "Los avances recientes en la teoría del cuerpo", REIS 68 (Revista Española de Investigaciones Sociológicas), octubre-diciembre, Centro de Investigaciones Sociológicas, Madrid.

Valencia Villa, Hernando, 1997, Los Derechos Humanos, Acento Editorial, Madrid.

Varela, Francisco J. (edición y narración), 1997, El sueño, los sueños y la muerte, Exploración de la conciencia con SS el Dalai Lama, Mandala, Palma de Mallorca.

Vázquez, Rodolfo, 1999, "Ley, cuerpo y sujeto. Ética y clonación. Una perspectiva liberal”, Debate feminista, Año 10, Volumen 19, abril 1999, México, pp. 102-111. 
Weber, Renée, 1986, Diálogos entre cientificos y sabios, Los libros de la liebre de marzo, Barcelona, 1990.

Wobeser von, Gisela, 1999, Vida eterna y preocupaciones terrenales (las capellanias de misas en la Nueva España, 1700-1821), Universidad Nacional Autónoma de México, Instituto de Investigaciones Históricas, Serie Historia Novohispana/ 64, México.

Ziegler, Jean, 1976, Los vivos y la muerte, Siglo xxi, México.

\section{Otros documentos: boletines, revistas, memorias, folletos y documentos inéditos o de alcance restringido}

Ajuntament de Barcelona, Regidoria de Drets Civils, "Projecte de Carta Europea de salvaguarda dels Drets Humans a la ciutat", Proposta de la Comissió de Redacció/ Barcelona, 10 de diciembre 1999.

Ajuntament de Barcelona, Regidoria de Drets Civils, Versió definitiva de la "Carta Europea de salvaguarda dels Drets Humans a la ciutat", Versión aprobada en Saint-Denis, Francia, 18 de mayo de 2000. También en su página web, en español: www.bcn.es

Boletín de la Asociación Española Para el Derecho a Morir Dignamente, Número 45, Febrero 2000, Número extraordinario: Jornadas "Derecho a Morir Dignamente", Barcelona.
Castells, Pilar, 1997, “Ante la muerte estrategias heterónomas y autónomas" (Ponencia).

Coloquio "Preparación a la muerte", 1984, en Karmaling, Francia, Presentes: Kalu Rinpoché y médicos y psicólogos occidentales y religiosos de las tradiciones budista y cristiana.

Noticias Médicas, 2001, Número 3794, "Entrevista: Blanca Miranda Serrano, coordinadora nacional de trasplantes", Madrid, 8-14 junio 2001, pp. 12-13.

\section{Algunos artículos de la prensa, especialmente significativos}

La Vanguardia, "Nuestro cuerpo no es más que un instrumento que los genes utilizan para perpetuarse", Entrevista a Richard Dawkins, biólogo evolutivo, 27 febrero 2000, Barcelona, p. 42.

La Vanguardia, "La investigación sobre el genoma abre la vía a la inmortalidad, advierte un experto", 7 de abril 2000, Barcelona, p. 36.

La Vanguardia, La contra; "Nadie sabe qué es la vida", Entrevista a François Jacob, 28 de agosto de 2000, Barcelona, p. 28.

Nota de la autora: Todas las entrevistas de La Vanguardia pueden encontrarse en Internet (acceso gratuito), buscando a cualquiera del equipo autor: Lluis Amiguet, Inma Sanchís, Víctor Amela. 